\title{
La judicialización de las decisiones públicas: el caso de la política de moratoria turística de Canarias ${ }^{1}$
}

\author{
The judicialization of public decisions: the case of the moratorium on tourism \\ accommodation in the Canary Islands
}

\begin{abstract}
Moises Simancas Cruz (iD, Universidad de La Laguna, España. msimancas@ull.es
\end{abstract}
\section{RESUMEN}

La judicialización de las políticas públicas implica, básicamente, una reacción judicial cuando los actores "perjudicados" de su diseño e implementación consideran que sus derechos no están efectivamente garantizados por el poder ejecutivo o legislativo. Su introducción en el ciclo de las políticas públicas hace que el poder judicial adquiera una importante capacidad de interferencia e incidencia significativa en su reformulación. El objetivo principal de este trabajo es analizar la judicialización de las políticas turísticas. Para ello, nos basamos en una investigación empírica realizada bajo la metodología de estudio de caso sobre la judicialización de la política de moratoria turística implementada en el destino Islas Canarias (España). Entre los resultados obtenidos destacamos que la judicialización supone la utilización de mecanismos legales por parte de los actores "perjudicados" de las decisiones judiciales, administrativas o legislativas (hard law) sobre la que suele sustentarse las políticas públicas turísticas. Asimismo, se produce cuando existen fallos en el proceso de formulación de tales políticas públicas. Del mismo modo, constituye un ejercicio de intrusión de los tribunales de justicia en un terreno reservado a los poderes ejecutivo y legislativo, con la consiguiente tensión entre política y justicia; ello supone un desplazamiento de protagonismo desde el poder legislativo al judicial, a la vez que una pérdida de centralidad de la autoridad legislativa, cuyo ejercicio y poder quedan limitados y regulados.

Palabras claves: judicialización, moratoria turística, poder judicial, políticas públicas

\footnotetext{
1. La investigación que da lugar a este trabajo constituye uno de los resultados del proyecto "Análisis de la sostenibilidad urbana como estrategia de regeneración del espacio público de las áreas turísticas de litoral", financiado por la Fundación CajaCanarias y gestionado por el Vicerrectorado de Investigación de la Universidad de La Laguna.
} 


\section{The judicialization of public decisions: the case of the moratorium on tourism accommodation in the Canary Islands}

\section{SUMMARY}

The judicialization of public policies basically implies a judicial reaction when the agents who have been "wronged" by their design and implementation consider that their rights are not effectively guaranteed by the executive or legislative power. Its introduction into the cycle of public policies means that the judiciary acquires considerable capacity for interference and has a significant impact on the reformulation of these policies. The main objective of this research is to analyze the judicialization of tourism policies. To do this, it is based on an empirical study conducted according to the case study methodology on the judicialization of the tourism moratorium implemented in the Canary Islands (Spain). Among the results obtained, we can highlight that judicialization involves the use of legal mechanisms by the parties "harmed" by the hard law on which public tourism policies are usually based. It also occurs when there are failures in the process of formulating such public policies. In the same way, it constitutes an exercise of intrusion by the courts of justice in an area reserved for the executive and legislative powers, with the consequent tension between politics and justice; this means that the leading role shifts from the legislative to the judicial power and there is a loss of centrality of the legislative authority whose exercise and power are limited and regulated.

Keywords: judicialization, moratorium on tourism accommodation, judicial power, public policies

\section{INTRODUCCIÓN}

La gobernabilidad del turismo define las condiciones sistémicas e institucionales bajo las cuales el sector público ejerce su legítimo poder. Por ello el éxito de cualquier política turística se sustenta en la colaboración, negociación, consenso y compromiso entre los actores públicos y privados. Sin embargo, determinadas partes interesadas o alianzas de grupos de interés aprovechan su capacidad (poder) para influir de forma sustancial en los resultados de la política pública (Marzano y Scott, 2009). Ello les permite definir las reglas de acuerdo con la urgencia de sus demandas, así como fijar restricciones para la participación de otros actores. Esto hace que la aplicación de determinadas políticas turísticas genere dos tipos de actores privados. Por un lado, dicho grupo privilegiado, que, a modo de definitive stakeholders (Mitchell et al., 1997), está constituido por una minoría o élite que se organiza para resguardar sus intereses o avanzar en sus propios objetivos. Por otro, aquella parte interesada que no puede intervenir en el proceso de toma de decisiones para "hacer valer" sus intereses, al carecer del poder necesario. Esto hace que se sientan perjudicados o excluidos por tales políticas, lo que explica su rechazo a las mismas.

Esta asimetría da lugar a "ganadores" y "perdedores". Ello genera tensiones, controversias e interacciones antagónicas entre ambos tipos de actores, con los consiguientes desequilibrios y desigualdades de poder (Elliot, 1997; Dredge, 2010; Stevenson et al., 2008). Ello crea un escenario de rivalidad, confrontación, incompatibilidad o disfuncionalidad entre 
los distintos grupos de interés, dando lugar a conflictos. Resulta habitual que los perdedores reaccionen canalizando sus demandas hacia la competencia judicial (Ferejohn, 2002) cuando las partes en litigio están tan cerradas en sus posiciones y no intentan trabajar voluntariamente juntas para buscar una solución y resolver tales desacuerdos. Ello genera un contexto de litigación de las relaciones entre la Administración y los administrados, con la consiguiente intervención de los juzgados. Así, surgen los procesos de judicialización.

A diferencia de la involucración del poder judicial "desde arriba", produciéndose "la politización de la justicia" (Ferejohn, 2002; Couso, 2004; Domingo, 2004; Ansolabehere, 2005; O'Donnell, 2005; Sieder, Schjolden y Angell, 2011) o el "activismo judicial" (Hennig, 2012; Feoli, 2014), la judicialización "desde abajo" se produce cuando los actores "perdedores" invocan a los tribunales de justicia, sobre todo, de las instancias superiores, para resolver sus demandas a través de procedimientos judiciales en forma de sentencias o similares, en cuanto no encuentran salidas o respuestas a los conflictos derivados de sus determinaciones. Esto determina que las decisiones de los tribunales de justicia competentes sean las que resuelven los conflictos derivados de las políticas públicas del turismo planteadas previamente por los poderes legislativos y propuestas por los ejecutivos. Esto obliga a su reformulación, e incluso, en algunos casos, a su inaplicabilidad. Además, el conocimiento de los motivos que origina tales conflictos y, sobre todo, de los intereses divergentes de los actores, resulta una tarea imprescindible para entenderlos $y$, por ende, gestionarlos y solucionarlos, o cuanto menos, mitigarlos.

El objetivo principal de este trabajo es analizar la judicialización de las políticas públicas en materia de turismo. Este objetivo convierte a este trabajo en relevante, en cuanto las relaciones y reacciones entre las disposiciones administrativas y los administrados constituyen una forma de medición de la conflictividad de una política turística. Además, si bien la judicialización de las decisiones públicas ha sido abordada desde diversos ámbitos académicos con diferentes enfoques (Tate y Vallinder, 1995; Gargarella, 1996; Waldron, 1999; Ferejohn, 2002; Guarnieri y Pederzoli, 2003; Couso, 2004; Domingo, 2004; Estévez, 2004; O’Donnell, 2005; Dente y Subirats, 2013; Feoli, 2014; Alvarez, 2015; Sieder, Schjolden y Angell, 2011; Boscán, 2010; Cámara, 2016; Marín, 2017), no ha sucedido lo mismo con la literatura relativa a la planificación territorial del turismo, destacando, entre otros, los trabajos de Elliot (1997), Jamal y Getz (2000), Dredge (2006 y 2010), Stevenson, Airey y Miller, 2008; Marzano y Scott (2009), Beritelli y Laesser (2011), Hall (2011), Yang et al. (2013), Valente, Dredge y Lohmann (2015), Velasco (2016) y Almeida et al. (2017).

Nos basamos en una investigación empírica realizada bajo la metodología de estudio de caso sobre la judicialización de la política de moratoria turística implementada en el destino Islas Canarias (España) a partir de 2001. Se trata de uno de los principales destinos turísticos vacacionales de litoral de Europa; prueba de ello es que, según el Instituto Canario de Estadística, recibió 15.975.507 visitantes en el año 2017, ocupando el primer puesto en el ranking de pernoctaciones en establecimientos turísticos de no residentes de la Unión Europea. En la medida en que el devenir de cualquier judicialización es un proceso que implica causas, componentes, actores, objetivos, acciones y reacciones, se ha optado por el enfoque de análisis de contenido o de correlato. De esta manera, el sujeto de observación de la investigación ha 
sido la propia moratoria turística y los momentos temporales definidos por su judicialización a través del conjunto de sentencias de la Sección 2 ${ }^{2}$ de la Sala de lo Contencioso Administrativo del Tribunal Superior de Justicia de Canarias (TSJC en los sucesivo), con sede en Las Palmas de Gran Canaria.

\section{LA JUDICIALIZACIÓN DE LA MORATORIA TURÍSTICA DE CANARIAS}

El denominado "tercer boom turístico", desarrollado en Canarias durante el segundo quinquenio de la década de los noventa, generó unas extraordinarias expectativas de crecimiento de la oferta de alojamiento turístico susceptibles de incorporarse al mercado en un plazo corto, medio y largo plazo. Así, existió el riesgo de pasar de las 354.435 plazas de alojamiento turístico con autorización de apertura existentes en el año 2000 a 596.368 en 2003 al incorporarse las que contaban con autorización previa en trámite, así como a un alarmante 1.109.720 al agregar aquellas sin ejecutar por hallarse en suelo aún sin desarrollar, aunque previstas en los planes urbanísticos, generales y parciales (Simancas, 2015).

La necesidad de corregir ese riesgo de sobreoferta de alojamiento turístico dio lugar a partir de 1999 a un intenso debate articulado en torno a la "desregulación liberalizadora del mercado versus intervencionismo público". Finalmente se optó por este último dando lugar a la denominada comúnmente como "moratoria turística". Se trata de un tipo de regulación pública dirigida a limitar o modular ese crecimiento cuantitativo de la oferta de alojamiento turístico, que se complementó con un conjunto de determinaciones dirigidas a la transformación sostenible del modelo turístico y la renovación del espacio público y privado de las áreas turísticas de litoral. Su dinámica ha presentado constantes cambios legislativos, desarrollándose en tres etapas como consecuencia, entre otras cuestiones, de diversas resoluciones judiciales.

\subsection{La judicialización de la primera moratoria turística (2001-2003)}

El proceso de moratoria turística se inició con el Decreto 4/2001, por el que se acordó la formulación de las Directrices de Ordenación General y las del Turismo. Este prohibió el otorgamiento de nuevas autorizaciones turísticas previas para obra nueva o para la ampliación de los alojamientos turísticos durante un año, prorrogable a otro, para las islas consolidadas turísticamente (Tenerife, Gran Canaria, Fuerteventura y Lanzarote) y de la mitad (seis meses), prolongable hasta un máximo de un año, para las denominadas "islas verdes" (La Palma, La Gomera y El Hierro). El leitmotiv de esta decisión fue evitar que el estado de tramitación del planeamiento urbanístico y, sobre todo, el otorgamiento de licencias por parte de los ayuntamientos turísticos, distorsionarán sustancialmente la situación territorial preoperacional a la aprobación de ambas Directrices, consolidándose un escenario incompatible con el modelo pretendido de ordenación territorial. No obstante, se permitió la construcción de hoteles con categoría mínima de cuatro estrellas que contasen con un tipo de la oferta complementaria de ocio (campo de golf, puerto deportivo o complejo temático o de salud). Ello supuso la 
habilitación no sólo de una alternativa, sino también una estrategia dirigida a la cualificación del modelo de alojamiento turístico.

El Decreto 4/2001 generó confusión, e incluso, incertidumbre a determinados actores. Sin embargo, el conflicto surgió cuando algunos percibieron que las excepciones eran consecuencia de la presión de un "grupo privilegiado", que procedió a la "captura del regulador", con el fin de resguardar sus intereses. Por tanto, su rechazo a las determinaciones del Decreto 4/2010 no derivó tanto de la diferencia de entender o comprender el problema generado por el tercer boom turístico o los objetivos de esta norma, sino de las discrepancias para fijar quienes iban a ser los beneficiarios de sus determinaciones.

Del mismo modo, el Gobierno de Canarias planteó que esta medida de contención del crecimiento de la oferta de alojamiento turístico no generaba indemnizaciones por la merma de derechos o expectativas. Así, se intentó cambiar el modelo turístico y extinguir derechos adquiridos - y, por tanto, consolidados- de particulares, en concreto, los relativos a los suelos turísticos que no fueron desclasificados, "sin pagar por ello". Con ello se incumplió la premisa jurídica básica de que cualquier restricción del ejercicio de derechos consolidados, la relativa a la formulación de alternativas que minimizasen o compensasen tal limitación.

Ambas cuestiones hicieron que el Decreto 4/2001 acumulase 31 recursos contencioso-administrativos en el TSJC. Como se puede apreciar en el cuadro 1, la mayoría de los recurrentes fueron entidades mercantiles vinculadas con el lobby empresarial de la construcción y la promoción inmobiliaria constituidas durante el tercer boom turístico; ello evidencia que éste no estuvo liderado, en su mayoría, por emprendedores turísticos, sino por promotores urbanísticos. Estos presentaron tales recursos al ver frustradas sus expectativas inmobiliarias, con el fin de reclamar indemnizaciones, aludiendo a la responsabilidad patrimonial de la Administración Autonómica. Esta reacción por la vía judicial dio cuenta de una situación dual: mientras que las acciones acometidas desde el Gobierno de Canarias se circunscribieron en los procesos de reconfiguración del escenario turístico y surgimiento de nuevas relaciones destino-mercado, los promotores privados siguieron la lógica inmobiliario-turística de crecimiento y del beneficio individual. Este comportamiento contrario a la decisión pública de contener el crecimiento cuantitativo de la oferta de alojamiento turístico complicó las posibilidades de lograr los objetivos previstos con la misma; el error fue esperar de los agentes económicos algo que corresponde más bien a los promotores turísticos. 
Cuadro 1. Recursos interpuestos contra el Decreto 4/2001 ante la Sala del Tribunal Superior de Justicia de Canarias

\begin{tabular}{|c|c|c|c|c|}
\hline $\begin{array}{l}\text { Naturaleza } \\
\text { de los } \\
\text { recurrentes }\end{array}$ & $\begin{array}{l}\text { Número de } \\
\text { recurso }\end{array}$ & Recurrente & $\begin{array}{l}\text { Actividad con la } \\
\text { empresa recurrente } \\
\text { está inscrita en la } \\
\text { Clasificación Nacional } \\
\text { de Actividades } \\
\text { Económicas }\end{array}$ & $\begin{array}{l}\text { Año de constitución de } \\
\text { la empresa recurrente }\end{array}$ \\
\hline \multirow{2}{*}{$\begin{array}{l}\text { Entidades } \\
\text { públicas }\end{array}$} & $521 / 2001$ & Ayuntamiento de Mogán & - & - \\
\hline & $567 / 2001$ & Ayuntamiento de La Oliva & - & - \\
\hline \multirow{29}{*}{$\begin{array}{l}\text { Entidades } \\
\text { privadas }\end{array}$} & $271 / 2001$ & $\begin{array}{l}\text { Asociación de Empresarios de la } \\
\text { Construcción }\end{array}$ & - & - \\
\hline & $425 / 2001$ & Selenium Construct, S.L. & 4110 & 1999 \\
\hline & $489 / 2001$ & $\begin{array}{l}\text { Flamenco Tenerife Inmobiliaria y Obras, } \\
\text { S.L. }\end{array}$ & 4121 & 2000 \\
\hline & $517 / 2001$ & Archipiélago y Turismo, S.A. (ARTURSA) & 5510 & 1991 \\
\hline & $525 / 2001$ & Inmobarrenda, S.L. & 4110 & 1996 \\
\hline & $526 / 2001$ & Nicica, S.L. & 4110 & 1996 \\
\hline & $558 / 2001$ & Lopesan Touristik, S.A. [Grupo Lopesan] & 7490 & 1996 \\
\hline & $559 / 2001$ & Centro Helioterápico de Canarias, S.A. & 5510 & 1968 \\
\hline & $560 / 2001$ & $\begin{array}{c}\text { Insular Canaria de Promociones } \\
\text { Inmobiliarias, S.A. (Incapisa) }\end{array}$ & 7010 & 1981 \\
\hline & $561 / 2001$ & Servando López Peláez y otros & - & - \\
\hline & $562 / 2001$ & Anduriña, S.A. & 4110 & 1988 \\
\hline & $578 / 2001$ & Dehesa de Jandía, S.A. & 4110 & 1991 \\
\hline & $579 / 2001$ & $\begin{array}{c}\text { Maspalomas Resort, S.L. [Grupo } \\
\text { Lopesan] }\end{array}$ & 5510 & 1995 \\
\hline & $580 / 2001$ & Maspalomas Golf, S.A. [Grupo Lopesan] & 9311 & 1981 \\
\hline & $581 / 2001$ & $\begin{array}{l}\text { Hijos de Francisco López Sánchez, S.A. } \\
\text { [Grupo Lopesan] }\end{array}$ & 4110 & 1972 \\
\hline & $582 / 2001$ & D. Lorenzo Betancor Curbelo y otros & - & - \\
\hline & $584 / 2001$ & Puerto Rico, S.A. & 4121 & 1967 \\
\hline & $593 / 2001$ & Matas Blancas, S.A. & & - \\
\hline & $598 / 2001$ & Hoteles Piñero Canarias, S.L. & 5510 & 1994 \\
\hline & $601 / 2001$ & Salobre Golf Hoteles, S.A. & 5510 & 2000 \\
\hline & $602 / 2001$ & Golf El Salobre, A.I.E & 7022 & 1993 \\
\hline & $603 / 2001$ & $\begin{array}{l}\text { D. Eufemiano y Dña. Carmen Rodríguez } \\
\text { Marrero }\end{array}$ & - & \\
\hline & $617 / 2001$ & Canarias Sol, S.A. & 4121 & 1988 \\
\hline & $625 / 2001$ & Hermanos Santana Cazorla, S.L. & 4299 & \\
\hline & $787 / 2001$ & Tenerife Inmobiliaria y otras, S.L & & \\
\hline & $792 / 2001$ & Complejo El Carmen, S.L. & 4121 & 1997 \\
\hline & $793 / 2001$ & $\begin{array}{l}\text { Federación Provincial de Entidades de la } \\
\text { Construcción de Santa Cruz de Tenerife }\end{array}$ & - & - \\
\hline & $877 / 2001$ & $\begin{array}{c}\text { Junta de Compensación de los Polígonos } \\
\text { 10, } 11 \text { y } 12 \text { del Plan Parcial Playa de } \\
\text { Mogán }\end{array}$ & - & - \\
\hline & $1.615 / 2001$ & $\begin{array}{l}\text { Flamenco Tenerife Inmobiliaria y Otras, } \\
\text { S.L }\end{array}$ & 4121 & 2000 \\
\hline
\end{tabular}

4110 Promoción inmobiliaria

4121 Construcción de edificios residenciales

4299 Construcción de otros proyectos de ingeniería civil n.c.o.p.

5510 Hoteles y alojamientos similares
7010 Actividades de las sedes centrales

7022 Otras actividades de consultoría de gestión empresarial

7490 Otras actividades profesionales, científicas y técnicas n.c.o.p.

9311 Gestión de instalaciones deportivas

Fuente: Tribunal Superior de Justicia de Canarias / Boletín Oficial de Canarias / Registro Mercantil.

Elaboración propia. 
Estos recursos contencioso-administrativos fueron desestimados total o parcialmente por la Sala del TSJC. Entre los argumentos esbozados se encontró el hecho de que estos recursos no eran coherentes con los supuestos indemnizatorios considerados en la Sentencia del Tribunal Supremo de 12 de mayo de 1987, esto es, cuando la alteración afectaba a un plan en su fase final de realización, no se había ejecutado dentro del plazo establecido por razones imputables a la Administración o los requisitos o cargas de la ordenación anterior se habían cumplidos.

Sin embargo, la contestación más importante al Decreto 4/2001 fue la del Auto de 25 de mayo de 2001 del TSJC, hecho público con fecha de 28 de mayo. Se trató de la pieza separada del recurso contencioso-administrativo número 792/2001 presentado por el Complejo El Carmen, S.L. Éste determinó la suspensión cautelar de la ejecutividad de la norma recurrida en función de tres fundamentos.

El primero fue la incidencia directa de sus determinaciones sobre los intereses del sector turístico. El propio Auto planteó que el Decreto era consecuencia "de una desorientada política turística, en la que se comprometen sustanciosas inversiones inmobiliarias sin existir planes o modelos en los que participe el sector turístico".

El segundo aludió a que la eficacia del Decreto producía perjuicios irreparables. Así, planteó la posibilidad de que los costos del resarcimiento de los perjudicados iban a alcanzar cotas mucho más altas ante la probable avalancha de solicitudes de indemnizaciones en caso de prosperar el resto de los recursos interpuestos contra el Decreto. De esta manera, el TSJC reconoció las medidas autonómicas de contención del crecimiento turístico generaban la responsabilidad patrimonial del Gobierno de Canarias.

El tercero fue la inexistencia de "apariencia de buen derecho", planteando dudas razonables acerca de la viabilidad y legalidad del Decreto 4/2001. De esta manera, el TSJC sancionó lo jurídicamente reprobable, sin estar indicado para juzgar la competencia política. Ello se justificó por las siguientes cuestiones:

a. La falta de motivación de las razones por la que tal restricción temporal se adoptó, a la vez que una reflexión previa en función del desarrollo turístico de cada isla.

b. La restricción temporal sólo podía haber sido adoptada por los órganos competentes durante la formulación y tramitación de las Directrices de Ordenación del Turismo (DOT en lo sucesivo) y no de forma preparatoria. Con ello se planteó la ilegalidad, arbitrariedad e irretroactividad de la suspensión.

c. La falta de una cobertura normativa para el desarrollo de la iniciativa impugnada, en cuanto los artículos 14, 15 y 16 del Decreto Legislativo 1/2000, de 8 de mayo, por el que se aprueba el Texto Refundido de las Leyes 9/1999, de Ordenación del Territorio de Canarias, y 12/1994, de Espacios Naturales de Canarias (TRLOTENC en lo sucesivo) no recogían el procedimiento legal para formar y aprobar las DOT.

d. No se ajustó al citado TRLOTENC, Ilegando, incluso, a contravenirlo, a pesar de producirse una constante alusión al mismo.

e. La indeterminación de la suspensión a través de un simple decreto. 
f. La incertidumbre acerca de la naturaleza de la norma recurrida, dudando si era un acto o un reglamento. En este sentido, se consideró que, si bien el TRLOTENC preveía el desarrollo reglamentario de las DOT, el Gobierno decidió el desarrollo directo sin programación normativa previa. Con ello se produjo la "más absoluta de las anomalías posibles", pues el vacío normativo de la ley "no puede ser cubierto por la escuálida regulación que se contiene en el Decreto".

g. La necesidad que el interés público de las solicitudes de licencias al amparo del planeamiento urbanístico en vigor era merecedor de una mayor tutela jurídica frente al interés público ínsito en la voluntad política de iniciar la tramitación de las DOT.

h. La vulneración de las premisas jurídicas básicas de que cualquier restricción del ejercicio de derechos consolidados; nos referimos, por una parte, a la necesidad de tener un alcance estrictamente necesario, por lo cual es precisa la observación del principio de proporcionalidad, y por otra, que el sacrificio exigido fuera el imprescindible para la obtención del interés general perseguido con la norma.

i. La infracción del principio de seguridad jurídica y confianza legítima.

j. La vulneración del principio de objetividad e igualdad, produciéndose discriminaciones respecto a los usos turísticos no suspendidos, así como a las medidas adoptadas para las "islas verdes".

Con posterioridad, el 20 de julio de 2001, el TSJC hizo público otro Auto por el que mantuvo dicha suspensión cautelar. De esta manera, el recurso de súplica presentado el 28 de mayo por la Dirección General del Servicio Jurídico del Ejecutivo autonómico quedó desestimado. Finalmente, el Decreto 4/2001 fue declarado nulo de pleno derecho. Así, la vigencia del primer decreto de moratoria turística apenas fue de cuatro meses.

Esta decisión judicial dejó sin efectos las medidas cautelares previstas en el Decreto 4/2001 para la formulación de las Directrices y, por ende, la suspensión de los procedimientos de aprobación de los instrumentos de ordenación previstos en el TRLOTENC de igual o inferior rango a las mismas y de otorgamiento de licencias urbanísticas. Aprovechando este "vacío legal", los Ayuntamientos de Adeje y San Miguel de Abona (Tenerife) y de Pájara, La Oliva y Antigua (Fuerteventura) convocaron plenos extraordinarios y urgentes a lo largo del día 28 de mayo de 2001, desarrollándose algunos, incluso, en horario nocturno. En ellos se concedieron licencias de obras a proyectos urbanísticos que, contando con autorización turística previa y con expediente administrativo avanzado estaban paralizados en virtud del Decreto 4/2001.

Los Servicios Jurídicos de la Comunidad Autónoma interpusieron siete recursos contencioso-administrativos contra esos cinco ayuntamientos. Éstos se fundamentaron, entre otras cuestiones, en el interés general de la ordenación de las áreas turísticas recogido en el Decreto 4/2001, el carácter cautelar - no anulatorio- de su suspensión, así como el hecho de que se trató de una medida dirigida a evitar la consolidación de nuevas situaciones de transformación del suelo antes de la aprobación de las DOT. Estos argumentos fueron objetados por el TSJC, en base a dos cuestiones: por una parte, dicho interés general no se podía alegar en un decreto que había sido suspendido, de modo que "aparece ausente de cobertura legal" 
y "tiene indicios de nulidad"; y por otra, que "existía el deber de proteger el interés general de un municipio que había concedido una licencia de acuerdo con su planeamiento urbanístico en vigor".

Finalmente, el TSJC declaró la nulidad del Decreto 4/2001 en la sentencia de 19 de diciembre del 2002, al resolver el recurso directo interpuesto contra el mismo (número 271/2001); ésta fue recurrida en casación. Algunos de los argumentos absolutamente contundentes de esta sentencia fueron los siguientes:

a. El Decreto tenía carácter de disposición general, pues, como se ha señalado, aprobó el procedimiento para la redacción de las DOT.

b. Se dictó prescindiendo absolutamente del procedimiento legalmente previsto para la aprobación del indicado instrumento de ordenación territorial; según el artículo 14.5 del TRLOTENC, éste debía desarrollarse reglamentariamente.

c. La no aplicabilidad del derecho estatal como derecho supletorio, al ser las Directrices un instrumento de ordenación propio del Derecho autonómico.

d. La vulneración del principio de autonomía local, al no contar con el parecer de las administraciones municipales. Así, llegó a calificar el acto de "fraude de ley", al eludir las vías reglamentarias donde tendrían cabida los pareceres que afectaban a competencias exclusivas y/ o compartidas.

El Auto del TSJC de suspensión cautelar del Decreto 4/2001 dio un giro judicial al ya complicado proceso de moratoria turística. Al día siguiente ( 28 de mayo de 2001 ) a que se notificara a las partes, se produjo un procedimiento totalmente infrecuente e inaudito: dos números del Boletín Oficial de Canarias se publicaron el mismo día, mediando horas entre su edición. Así, mientras en el número 65 se hicieron públicas cinco Resoluciones de la Sala de lo Contencioso-Administrativo de los recursos interpuestos contra el Decreto 4/2001, en el número 66 se promulgó el Decreto 126/2001, de 28 de mayo, por el que se suspendió la vigencia de las determinaciones turísticas de los Planes Insulares de Ordenación (escala insular) y de los instrumentos de planeamiento urbanístico (escala municipal) en el ámbito territorial de Fuerteventura, Gran Canaria y Tenerife. Asimismo, prácticamente sin solución de continuidad, se dictó el Decreto 127/2001, de 5 de junio, por el que se regularon ambas Directrices de Ordenación, publicándose el mismo día de su aprobación (Boletín Oficial de Canarias, número 71 , de 8 de junio). Esto supuso un récord de celeridad nunca alcanzado por una Administración Pública canaria, demostrando una inusitada capacidad de reacción pública. Asimismo, constituyó una prueba del comportamiento firme, el interés, el liderazgo político y la férrea voluntad del Gobierno de Canarias de seguir adelante con la política de moratoria turística y, sobre todo, con el proyecto de aprobación de las Directrices General y del Turismo, en cuanto constituía el "proyecto estrella"" de la V Legislatura.

La promulgación de este segundo decreto de moratoria turística constituyó una estrategia habilitada por el Gobierno de Canarias para retornar a la situación preoperacional al Acto judicial del TSJC. Lo que se pretendió fue implantar, de nuevo, las previsiones del Decreto 4/2001 y, así, evitar las consecuencias de esa medida cautelar de suspensión y, sobre todo, del citado vacío legal; como es lógico, su aprobación no se justificó de este 
modo. Para ello, en lugar de fundamentarse en el TRLOTENC, se sustentó en el artículo 60 de la Ley 5/1999, de Ordenación del Turismo de Canarias. El resultado fue que, aunque formalmente tuvo un objeto diferente, en lo sustancial no difirió del Decreto 4/2001, teniendo las mismas consecuencias jurídicas. No sucedió lo mismo respecto al otorgamiento de nuevas autorizaciones, en cuanto las determinaciones de los instrumentos de ordenación territorial quedaron, de nuevo, congeladas. A su vez, se imposibilitó la concesión de las licencias solicitadas conforme al planeamiento vigente, eliminando cualquier excepción, en coherencia con la pretensión del Gobierno de Canarias de evitar cualquier posibilidad de que los ayuntamientos otorgasen licencias de edificación de obra nueva o de ampliación de los alojamientos turísticos.

Como se puede apreciar, el Decreto 126/2001 supuso una reacción preventiva del Ejecutivo canario al citado Auto; indudablemente no se hubiera promulgado si el TSJC no hubiera suspendido el 4/2001. Esta forma de proceder del ejecutivo canario no sólo constituyó un insólito modo de actuación respecto a la decisión judicial del TSJC. También supuso una clara y evidente intención de eludir el cumplimiento de su pronunciamiento, e incluso, de reemplazar su parecer; en este sentido, llama la atención que la respuesta del Consejo de Gobierno al citado Auto fuera otro decreto. Por esta razón, el TSJC entendió, con posterioridad, que las consecuencias del Decreto 126/2001 no diferían sustancialmente de las del 4/2001. Asimismo, señaló claramente en su Sentencia número 327/2003, de 19 de junio de 2003 que el objetivo del Decreto 126/2001 no fue otro que conseguir evitar las consecuencias de la suspensión judicial cautelar del Decreto 4/2001 y rehabilita sus medidas cautelares. Ello explica que calificase su promulgación como "una desviación de poder para fines distintos a los previstos por la norma".

Lo anterior explica que el Decreto 126/2001 tuviera una respuesta judicial. La sentencia dictada por el TSJC en relación con el recurso 1.177/2001, interpuesto por el Ayuntamiento de Mogán, abrió la vía a la presentación ante esa Sala de otros 14 recursos contencioso-administrativos que recurrieron su legalidad (cuadro 2). Los recurrentes reclamaron al Gobierno de Canarias indemnizaciones por suspensión injustificada de derechos ya adquiridos. Estos recursos dan cuenta como el Decreto 126/2001 no sólo acentuó el conflicto, sino que incrementó la desconfianza, la parcialidad y la cerrazón de las partes en litigio. 
Cuadro 2. Recursos interpuestos contra el Decreto 126/2001 ante la Sala del Tribunal Superior de Justicia de Canarias

\begin{tabular}{|c|c|c|c|c|}
\hline $\begin{array}{l}\text { Naturaleza } \\
\text { de los } \\
\text { recurrentes }\end{array}$ & $\begin{array}{l}\text { Número de } \\
\text { recurso }\end{array}$ & Recurrente & $\begin{array}{l}\text { Actividad con la } \\
\text { empresa recurrente } \\
\text { está inscrita en la } \\
\text { Clasificación Nacional } \\
\text { de Actividades } \\
\text { Económicas }\end{array}$ & $\begin{array}{l}\text { Año de constitución de } \\
\text { la empresa recurrente }\end{array}$ \\
\hline \multirow{3}{*}{$\begin{array}{l}\text { Entidades } \\
\text { públicas }\end{array}$} & $986 / 2001$ & Ayuntamiento de La Oliva & - & - \\
\hline & $1.177 / 2001$ & Ayuntamiento de Mogán & - & - \\
\hline & $16 / 2002$ & Ayuntamiento de San Miguel de Abona & - & - \\
\hline \multirow{12}{*}{$\begin{array}{l}\text { Entidades } \\
\text { privadas }\end{array}$} & $1.037 / 2001$ & Golf El Salobre, A.I.E & 7022 & 1993 \\
\hline & $1.057 / 2001$ & Yudaya, S.A. & 6820 & 1988 \\
\hline & $1.213 / 2001$ & Lorenzo Betancor Curbelo y otros & - & - \\
\hline & $1.216 / 2001$ & Anduriña, S.A. & 4110 & 1988 \\
\hline & $1.232 / 2001$ & Maspalomas Golf, S.A & 5510 & 1981 \\
\hline & $1.234 / 2001$ & Hermanos Santana Cazorla, S.L. & 4299 & \\
\hline & $1.240 / 2001$ & $\begin{array}{l}\text { Insular Canaria de Promociones } \\
\text { Inmobiliaria S.A. (Incapisa) }\end{array}$ & & 1981 \\
\hline & $1.243 / 2001$ & $\begin{array}{c}\text { Entidad Centro Helioterápico de } \\
\text { Canarias S.A. } \\
\end{array}$ & 5510 & 1968 \\
\hline & $1.244 / 2001$ & $\begin{array}{c}\text { Servando López Peláez Club Beach } \\
\text { Inmobiliaria, S.L, Inmobiliaria Furelos, } \\
\text { S.A., Somotur, S.A. y otros }\end{array}$ & - & - \\
\hline & $1.261 / 2001$ & Puerto Rico, S.A., & 4121 & 1967 \\
\hline & $1.293 / 2001$ & $\begin{array}{l}\text { Asociación de Empresarios de la } \\
\text { Construcción de Las Palmas }\end{array}$ & - & - \\
\hline & $86 / 2002$ & $\begin{array}{l}\text { Entidad Mercantil Complejo El Carmen } \\
\text { S.L. }\end{array}$ & 4121 & 1997 \\
\hline
\end{tabular}

4110 Promoción inmobiliaria

4121 Construcción de edificios residenciales

4299 Construcción de otros proyectos de ingeniería civil n.c.o.p.

5510 Hoteles y alojamientos similares
6820 Alquiler de bienes inmobiliarios por cuenta propia 7010 Actividades de las sedes centrales

7022 Otras actividades de consultoría de gestión empresarial 9311 Gestión de instalaciones deportivas

Fuente: Tribunal Superior de Justicia de Canarias / Boletín Oficial de Canarias / Registro Mercantil. Elaboración propia.

Al igual que sucedió con el Decreto 4/2001, las sentencias del TSJC impugnaron y declararon nulo el segundo Decreto; resulta relevante que la presidenta firmó las sentencias, aunque emitió un voto particular, desestimando los recursos contencioso-administrativos interpuestos. Éstas fueron confirmadas, en todos sus aspectos, por el Tribunal Supremo en octubre de 2008, apuntando que "el Gobierno autónomo había incurrido en desviación de poder, esto es, que había ejercido sus potestades para fines distintos a los previstos por la ley".

Sin perjuicio del éxito de tales impugnaciones jurisdiccionales y sin solución de continuidad y aplicación del Decreto 126/2001 -únicamente habían pasado 29 días desde su publicación-, se aprobó la Ley 6/2001, de 23 de julio, de Medidas Urgentes en materia de Ordenación del Territorio y del Turismo de Canarias. Esta ley se planteó como la forma de acabar con la improvisación, precipitación, indefinición e inseguridad jurídica que hasta ese momento había caracterizo al proceso de moratoria turística "vía decretazos"; ello constituyó una nueva muestra de la insistencia y voluntad del Gobierno de Canarias en su propósito de incidir sobre el crecimiento de la oferta de alojamiento turístico. Del mismo modo, se proyectó 
como una "ley puente" (Fajardo, 2006), a modo de tránsito hacia la situación que las DOT debían instaurar, así como un mecanismo de blindaje durante el procedimiento de su formulación. No obstante, se contemplaron, de nuevo, excepciones a estas medidas cautelares, en concreto, la construcción ilimitada de hoteles de más de cuatro estrellas y menos de 800 plazas, con equipamiento (campo de golf 18 hoyos par 70, puerto deportivo/parques temáticos o complejos deportivos y de salud), así como de cinco estrellas, con el fin de habilitar opciones para la incorporación de nuevos proyectos de alojamiento turístico.

El proceso de formulación y aprobación de ambas Directrices, fijado en el Decreto 176/2001, se caracterizó por una perfecta coordinación interadministrativa, que permitió culminarlo adecuadamente en el plazo previsto. Prueba de ello es que la redacción del texto inicial se hizo en cuatro meses y medio (del 1 de febrero al 10 de junio de 2002), sólo pasaron cinco meses desde la aprobación inicial ( 24 de junio) hasta la aprobación provisional y remisión al Parlamento de Canarias (4 de noviembre), la aprobación del texto final ( 5 de marzo de 2003) se produjo antes de cuatro meses y la Ley 19/2003 se promulgó un mes y medio después (11 de abril de 2003).

La Ley 19/2003, por la que se aprobaron ambas Directrices, se produjo por unanimidad de las fuerzas políticas del Parlamento de Canarias. Ello puede interpretarse como un ejercicio de responsabilidad de todo el arco político, consecuencia del esfuerzo de consenso realizado y del liderazgo político.

\subsection{La judicialización de la segunda moratoria turística (2003-2009)}

Tras las elecciones autonómicas de mayo de 2003, el gobierno de coalición resultante pareció que iba a seguir una línea continuista en la aplicación de ambas Directrices, al menos en relación con los actos formales de escasa trascendencia pública previstos en la Ley 19/2003 (García, 2007). Sin embargo, este ligero avance en la aplicación de las DOT quedó paralizado a finales del año 2004, hasta el punto de que desapareció prácticamente de la agenda política por las razones expuestas por Simancas (2015). Ello explica que casi la totalidad del amplio y ambicioso desarrollo instrumental y reglamentario previsto para la ordenación turística de las DOT y la Ley 19/2003 estaba por hacer al final de la VI Legislatura (2003-2007). Así, las Disposiciones Adicionales y Transitorias se convirtieron en definitivas. Ello convirtió a la moratoria turística en lo que Villar (2008) ha denominado como "derecho ornamental o ceremonial", al transformarla en un "derecho no aplicado" o "simbólico" (Villar, 2009).

Desde el punto de vista de la judicialización de la moratoria turística, esta desidia política afectó a la determinación de contemplada en la DOT 27 relativa a la revisión trienal de los límites y ritmos de crecimiento de la oferta de alojamiento turístico. De esta manera, la Ley 19/2003 se promulgó con una vigencia acotada en el tiempo, hasta el 16 de abril de 2006. De esta manera, este plazo se prorrogó automáticamente. Esto provocó la paralización sine diem de los aprovechamientos urbanísticos. Ello generó un escenario de incertidumbre para las empresas afectadas, con el consiguiente efecto negativo sobre las decisiones de inversión. El problema se agravó en la medida en que, en ningún momento, se dio la mínima certeza sobre cuando se iba a producir tal revisión. Ello resultó incoherente respecto 
al propio concepto de temporalidad o aplazamiento del término "moratoria". También contradijo los principios básicos de cualquier teoría y doctrina económica y jurídica de intervención pública en el mercado en relación con el hecho de que no debía ser permanente, teniendo una precisión temporal, que aportase la necesaria seguridad jurídica. Todo ello sin modificar la premisa inicial de que las restricciones de la moratoria turística no conllevaban indemnizaciones.

Esta situación dio lugar a la presentación de 14 reclamaciones de responsabilidad patrimonial, interpuestos en forma de recursos contencioso-administrativos contra el Gobierno de Canarias por parte de empresas vinculadas fundamentalmente con el lobby de la construcción (cuadro 3 y 4). Llama la atención que, a excepción del recurso de Veneguera, el resto lo hicieron en la misma fecha, el 15 de abril de 2004 y, por tanto, un día antes de que se cumpliera un año de la entrada en vigor de la Ley 19/2003. El objeto principal de estos recursos fue la estimación de la reclamación por indemnización de los daños y perjuicios causados por la paralización o congelación indefinida de sus respectivos proyectos turísticos por los bloques normativos de la primera (los Decretos 4/2001 y 126/2001, y la Ley 6/2001) y, sobre todo, de la segunda moratoria turística (Ley 19/2003), con las consiguientes suspensiones de licencias (6) o reclasificaciones de suelo (8). Como se puede apreciar, el problema no radicó en un defecto del instrumento (las DOT) y de la norma (la Ley 19/2003) -y, por ende, por la moratoria turística-, que quedaron ajenas al objeto de las reclamaciones de responsabilidad patrimonial cursadas. Por el contrario, se centraron en las Disposiciones Adicionales y Transitorias de Ley $19 / 2003$, en concreto, aquéllas que incidían de pleno en las clasificaciones del suelo para introducir ope legis desclasificaciones de sectores, en las medidas de caducidad de autorizaciones previas y licencias urbanísticas, así como en la prórroga de la suspensión del otorgamiento de nuevas autorizaciones y de aprobación y/o modificación del planeamiento turístico. Los reclamantes se ampararon fundamentalmente en que, aunque las medidas de contención del crecimiento de la oferta de alojamiento turístico contempladas en tales Disposiciones tenían inicialmente un carácter provisional, temporal y transitorio, al ceñirse únicamente al primer trienio siguiente a la aprobación de la Ley 19/2003, en la práctica, resultaron estáticas e indefinidas.

Por consiguiente, la falta de voluntad política y la negligencia observada por la Administración competente, con el consiguiente incumplimiento de los plazos, fueron los argumentos por los que se reconoció dicho perjuicio, al impedir la materialización de los aprovechamientos urbanísticos. Prueba de ello es que las sentencias se fundamentan en la dejadez no solo del Gobierno y del Parlamento de Canarias, sino también de los Cabildos Insulares de Fuerteventura y, sobre todo, Gran Canaria, en cuanto no habían cumplido con el mandato de aprobar sus Planes Territoriales Especiales de Ordenación Turística (escala insular); ello explica que ambas islas concentrasen las cinco sentencias, así como que este tipo de reclamaciones no se produjeron tanto en Tenerife, cuyo Cabildo aprobó su correspondiente Plan, como en Lanzarote, que desde 1989 contaba con su propia estrategia de moratoria turística. 


\begin{tabular}{|c|c|c|c|c|c|c|c|c|c|c|}
\hline \multicolumn{2}{|c|}{ 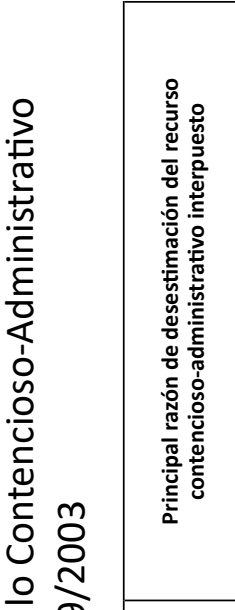 } & 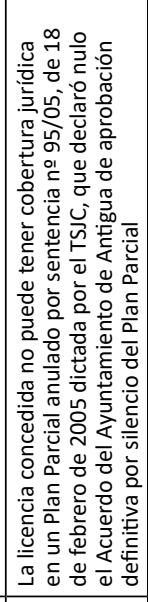 & 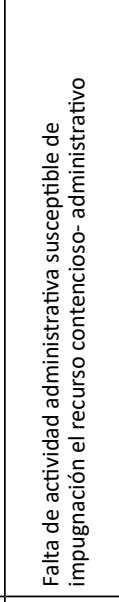 & 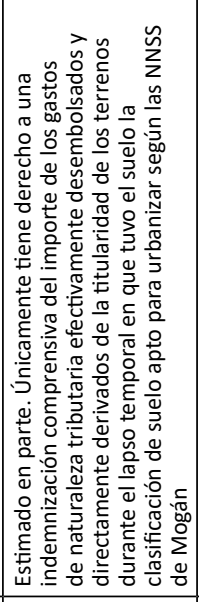 & 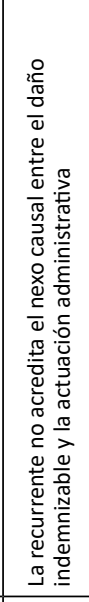 & 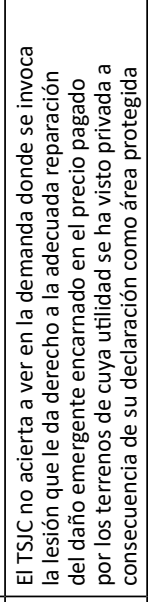 & 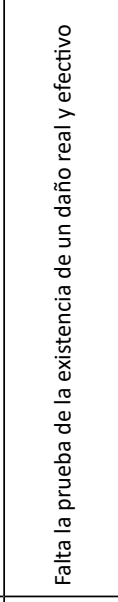 & 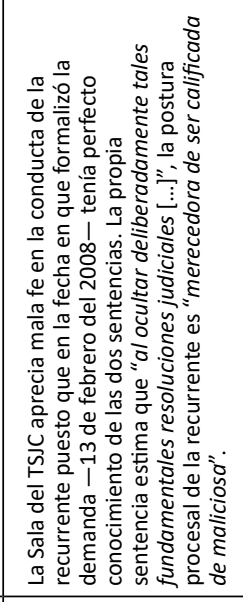 & 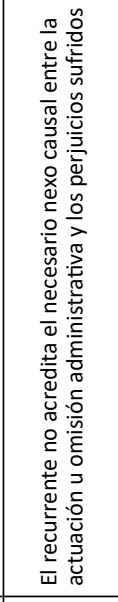 & 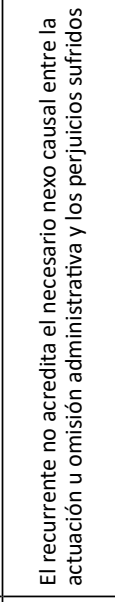 \\
\hline 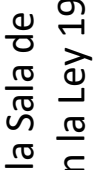 & 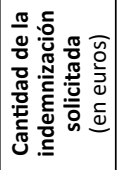 & 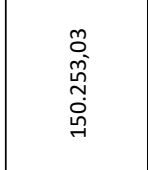 & 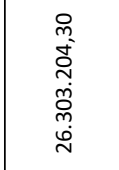 & 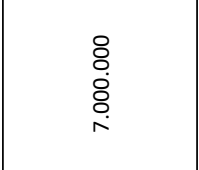 & 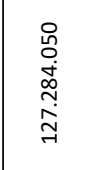 & 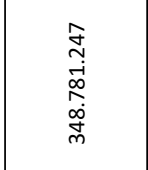 & 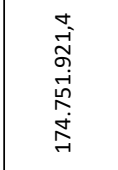 & $\begin{array}{l}\text { : } \\
\text { : } \\
\text { नें } \\
\text { 吕 }\end{array}$ & 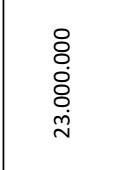 & 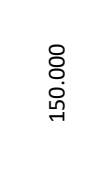 \\
\hline 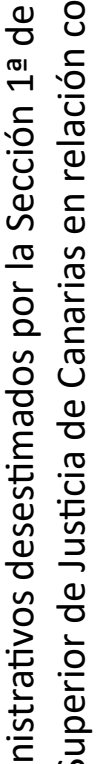 & 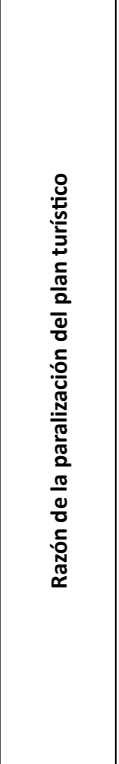 & 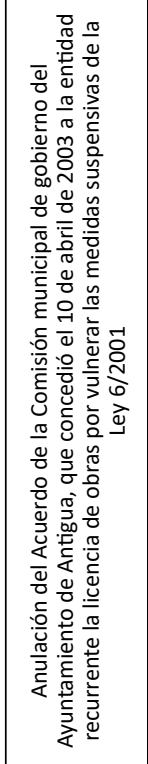 & 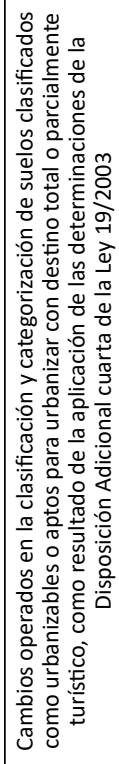 & 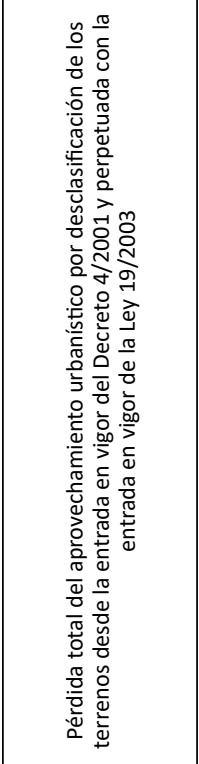 & 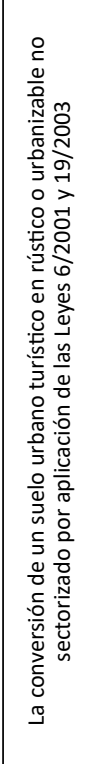 & 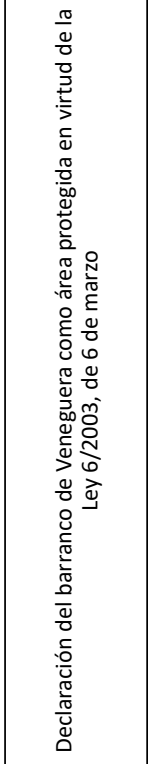 & 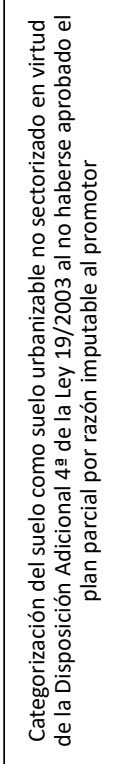 & 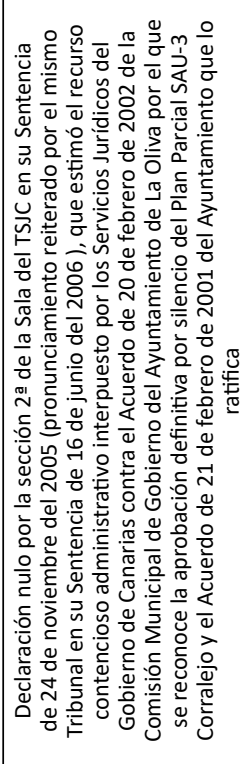 & 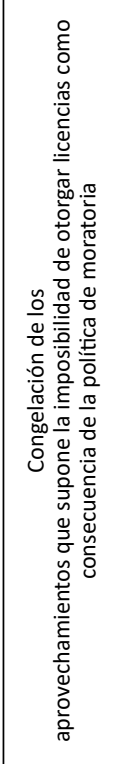 & 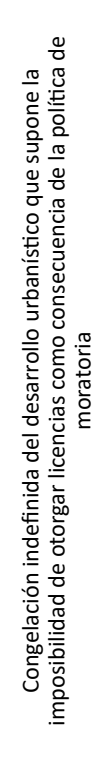 \\
\hline 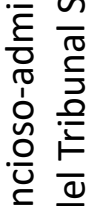 & 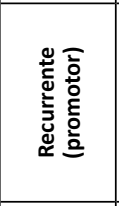 & 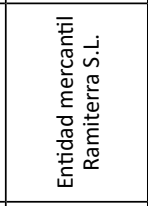 & 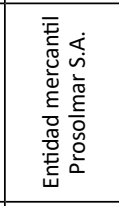 & 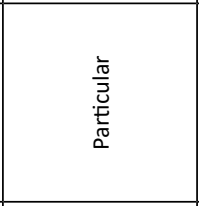 & 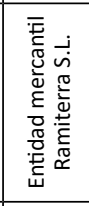 & 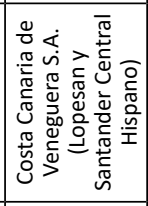 & 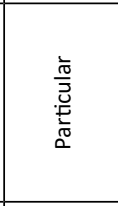 & 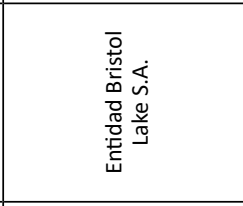 & 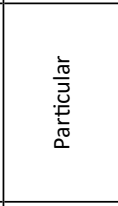 & 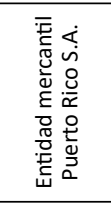 \\
\hline 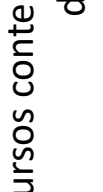 & 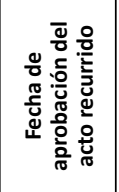 & 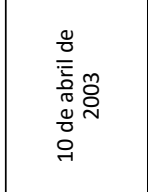 & 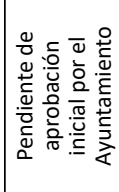 & 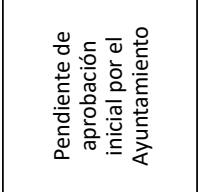 & 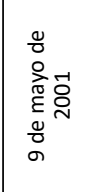 & 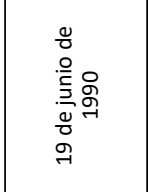 & 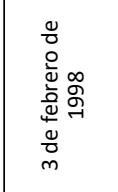 & 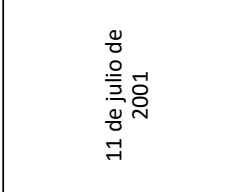 & 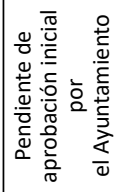 & 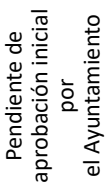 \\
\hline $\begin{array}{l}\mathscr{1} \\
\stackrel{1}{m} \\
\dot{m} \\
0\end{array}$ & 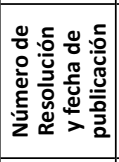 & 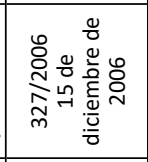 & 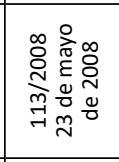 & 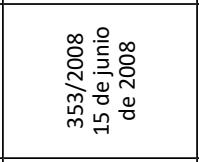 & 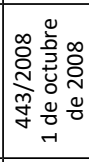 & 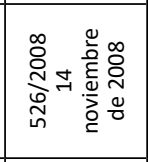 & 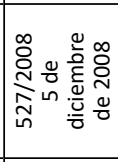 & 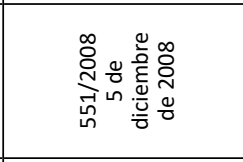 & 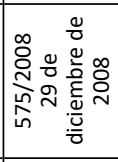 & 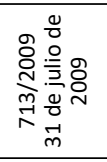 \\
\hline Uू & 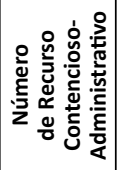 & 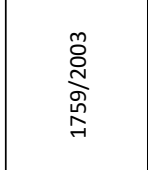 & 畩 & in & 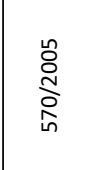 & 离 & 芯 & 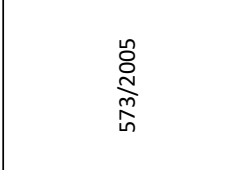 & 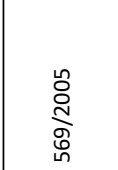 & 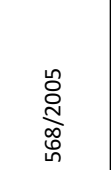 \\
\hline
\end{tabular}




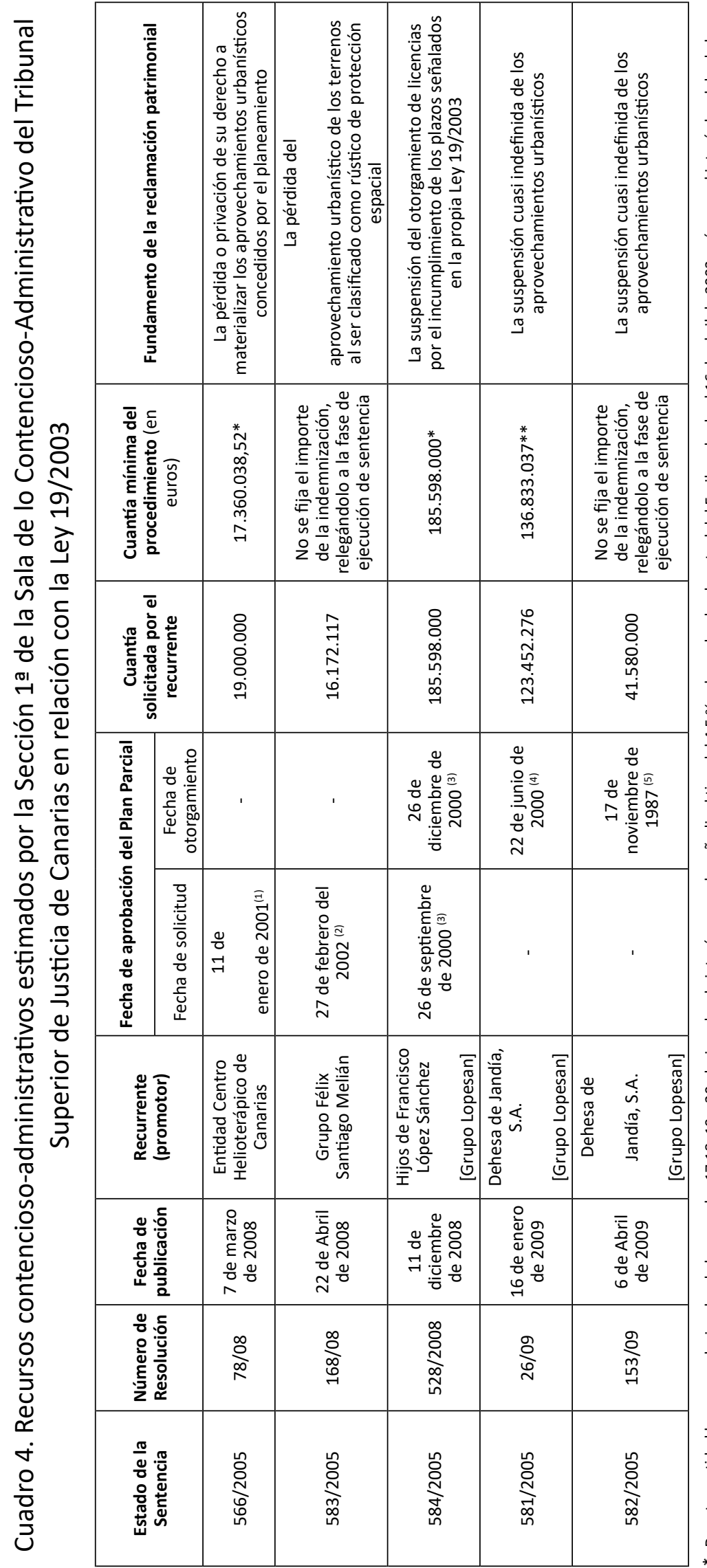

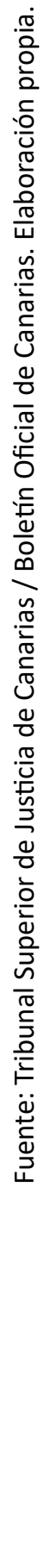


EI TSJC desestimó íntegramente nueve de esos recursos contencioso-administrativos. Estos solicitaban unas indemnizaciones por una cuantía de 914.530 .676 euros. Resulta de gran interés que su desestimación se fundamentó en cuestiones de forma, tales como que la compra del suelo se hizo con posterioridad a la entrada en vigor de la moratoria turística.

Las otras cinco sentencias estimadas dejaron más que prejuzgado que las medidas autonómicas de contención del crecimiento turístico daban lugar a una responsabilidad patrimonial del Gobierno de Canarias por los daños y perjuicios derivados de la paralización de sendos proyectos turísticos. Estas sentencias pusieron de manifiesto la irresponsable intervención pública durante el proceso de aplicación de la moratoria turística, al no considerar tanto los derechos adquiridos sobre el suelo, como la importancia del derecho romano en el poder judicial. Por tanto, dieron la razón a los promotores, que plantearon que tales medidas reflejaban la ineficacia del derecho constitucional de libertad de empresa, que prácticamente desapareció, en cuanto la actividad turística pasó a depender del criterio subjetivo de la administración pública y a ejercerse de acuerdo tanto a las exigencias de la economía general y de la planificación (artículo 38 de la Constitución española), como a la función social del derecho de propiedad (artículo 33.2 de la Constitución).

Estas sentencias determinaron la obligación de compensación por la existencia de una clara lesión patrimonial en aras del interés general interpretado por la Administración. Así, se estimó que los recurrentes no estaban obligados a soportar dicha paralización sin mediar la correspondiente indemnización. La cantidad total reclamada por los recurrentes fue de 385.802.393 euros, lo que supuso 22.558,9 euros por plaza turística paralizada. Ello contradijo el ya señalado argumento del Gobierno de Canarias de que la moratoria turística no generaba indemnizaciones.

Estas cinco sentencias acreditaron la existencia del daño, reconociendo el derecho a indemnización de los recurrentes. Así, fijaron la cuantía de las indemnizaciones de tres de los recursos en 339.791.076 euros $-y$, por tanto, 23.979, 6 euros por plaza paralizada-, relegando la de los otros dos casos a la fase de ejecución. A excepción de aquellos casos en los que una parte del proyecto turístico ya se había ejecutado, las sentencias no indemnizaron pérdidas económicas reales, sino expectativas derivadas de los derechos consolidados. Así, las sentencias constituyeron resoluciones estimatorias, que definieron las bases para la determinación de los correspondientes importes. Para ello establecieron un método propio para cuantificar el valor de la responsabilidad patrimonial. Éste se basó en dos conceptos indemnizables: por un lado, el lucro cesante, que supuso la estimación económica de la pérdida de una ganancia legítima $-y$, por tanto, de un perjuicio-, debido a la privación de los derechos urbanísticos incorporados al patrimonio de los recurrentes, con la consiguiente imposibilidad de poner en marcha una actividad empresarial, la de la explotación turística, inicialmente lícita y que contaba con todas las condiciones legalmente exigibles; y por otro, el daño emergente en relación con los gastos efectuados en la elaboración de los planes y proyectos. De esta manera, aunque la responsabilidad de los promotores se estimó parcialmente, no sucedió lo mismo con los derechos urbanísticos por considerarlos en suspenso. Así, aunque las sentencias descartaron que el importe de la reclamación fuera igual que los aprovechamientos urbanísticos, reconocieron y otorgaron un derecho a las entidades recurrentes a ser indemnizadas por no poder realizar la correspondiente actividad económica. 
En todos los fallos judiciales se optó por fijar la indemnización por una vía ciertamente novedosa: la aplicación del Interés Legal del Dinero desde el 16 de abril de 2003 -esto es, el día que la Ley 19/2003 entró en vigor - al importe total de los aprovechamientos lucrativos de las referidas parcelas, a determinar en ejecución de sentencia. Considerando que la indemnización final de daños y perjuicios que debía abonar la Comunidad Autónoma de Canarias se relacionó con el valor del suelo, su cuantía aumentó cada día, en cuanto las sentencias reconocieron que los promotores tenían paralizados sus proyectos urbanísticos hasta que cesara la moratoria turística. Asimismo, se consideró que el deudor había incurrido en mora, sin haberse pactado un tipo de interés determinado con anterioridad; así, la Comunidad Autónoma de Canarias debía abonar a esas cinco sociedades la cantidad de 30.950.947 euros sólo en concepto de intereses contabilizados desde la promulgación de la Ley 19/2003.

Lo anterior abrió la posibilidad que los empresarios recibieran indemnizaciones desorbitadas por actos con claros visos de especulación urbanística e induciendo procesos de rent seeking. Así, la no construcción del alojamiento turístico $-\mathrm{y}$, por ende, la no materialización de su derecho- resultó más rentable que si se hubieran ejecutado, en un momento de plena crisis de oferta y demanda turística. De esta manera, la negligencia y dejadez del Gobierno y del Parlamento de Canarias les resultó beneficiosa.

Las sentencias 78/2008, 528/2008 y $153 / 2009$ quedaron en ejecución provisional solicitadas por los recurrentes, siendo aceptadas por el TSJC. Ello supuso que, a falta del depósito del correspondiente aval bancario, el Gobierno de Canarias debía abonar, a modo de "pago a cuenta", unos 84 millones de euros (Diario La Provincia, de 28 de octubre de 2009). La reacción de los Servicios Jurídicos del Gobierno fue recurrirlas en súplica ante el Tribunal Supremo: mientras dos se desestimaron, anulando las Sentencias del TSJC que precisamente habían declarado la responsabilidad de la Administración autonómica por causa de la moratoria turística, la sentencia de 25 de enero de 2011 confirmó la 528/2008, denegando el recurso contencioso-administrativo interpuesto contra la desestimación presunta por silencio administrativo de la reclamación formulada.

Los Servicios Jurídicos de la Comunidad Autónoma y los propios promotores presentaron recursos de casación ante el Tribunal Supremo en relación con los fallos que estimaron de manera parcial las reclamaciones de los demandantes (6) y los recursos desestimados por el TSJC (5) y, que, por tanto, daban la razón al procedimiento seguido por la Administración (cuadro 5). Aquel emitió un total de once sentencias, bien anulando la decisión del órgano autonómico que daba la razón al promotor, bien ratificándola cuando desestimaba el derecho de indemnización. En lugar de utilizar razones vinculadas al interés general en el que se sustentó la estrategia de moratoria turística, estas sentencias se fundamentaron en tres defectos de formas: a) la solicitud de la indemnización se hizo de forma extemporánea; b) el incumplimiento de los plazos establecidos para la ejecución de los proyectos, para los que el promotor tenía una licencia concedida; y c) la inexistencia de derechos urbanísticos consolidados. Este último se convirtió en el quid de la cuestión. Así, el Tribunal Supremo determinó que, en aplicación del artículo 41 de la Ley 6/1998, sobre Régimen del Suelo y Valoraciones, la indemnización por la privación legislativa de derechos de carácter urbanístico derivada del cambio de ordenación del suelo establecido en la Disposición Adicional Cuarta de la Ley 19/2003 antes de transcurrir los plazos de ejecución del planeamiento o por limitaciones singulares que no 


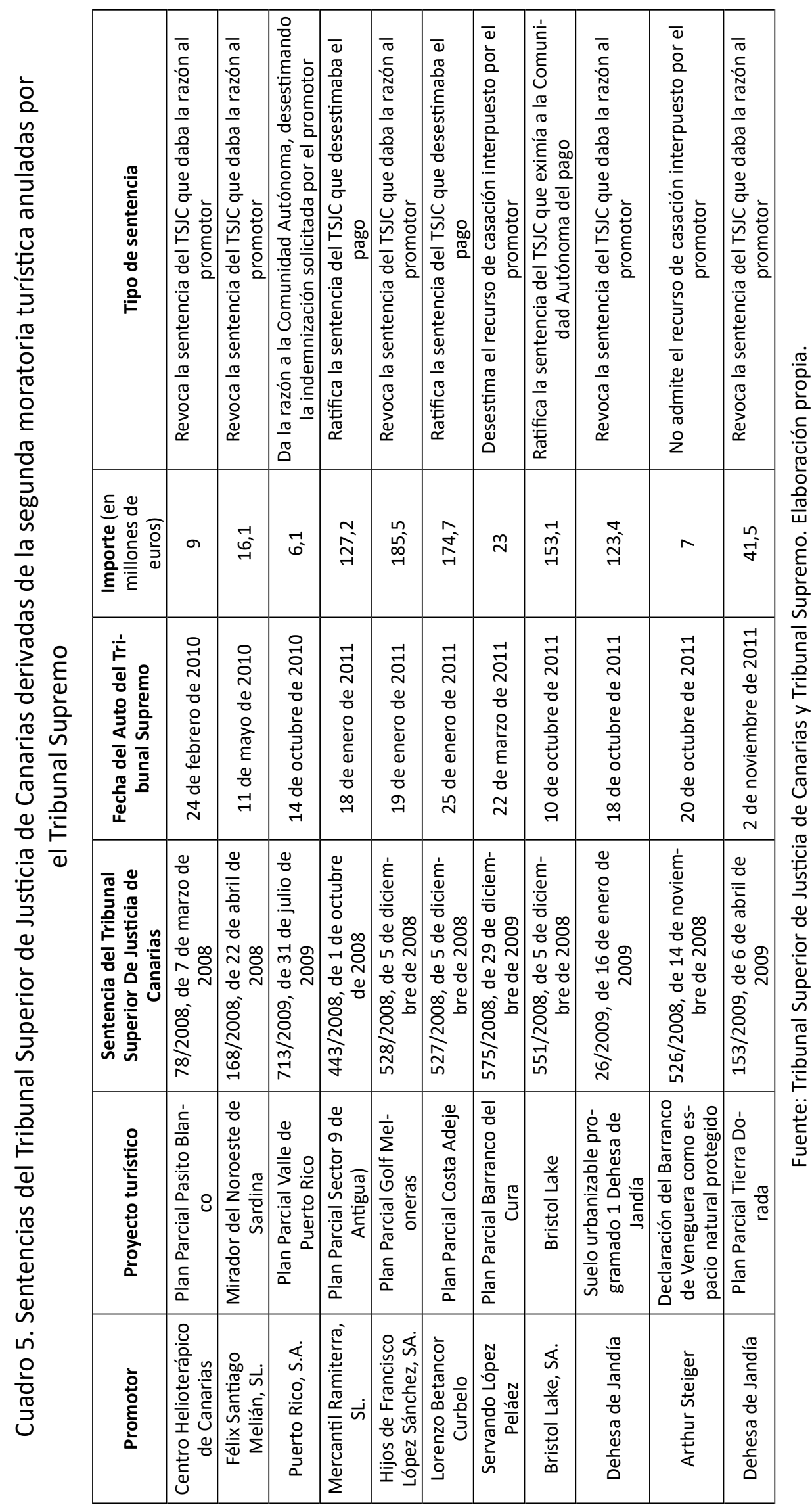


podían ser objeto de distribución equitativa en su ejecución, debían estar en congruencia con el grado del contenido patrimonial consolidado del que se privó a su propietario. Esta decisión se fundamentó en la premisa jurídica de que sobre los sectores en los que se produjeron tales cambios hubo una congelación o suspensión de los aprovechamientos por la simple razón de que no se había culminado el desarrollo del planeamiento urbanístico, con el consiguiente incumplimiento de los deberes que impone. En consecuencia, se consideró que no había existido lesión o perjuicio $-y$, por tanto, un sacrificio patrimonial individualizadoque diera lugar a derechos indemnizatorios. A este respecto, resulta interesante la diferencia de planteamiento entre el TSJC y el Tribunal Supremo: mientras el primero responsabilizó a la Administración Pública competente de la ausencia de aprobación del plan parcial, como consecuencia de vaivenes legislativos, los propios procedimientos, etc., el segundo lo imputó al promotor.

Con posterioridad, el Tribunal Supremo estimó que no concurría el requisito del carácter evaluable del daño en las cinco sentencias judiciales firmes del TSJC. Así, consideró que éste únicamente se origina cuando hay un auténtico quebranto patrimonial y no sólo cuando se producen perjuicios subjetivos, sin transcendencia económica objetiva que el particular tiene el deber jurídico de soportar, al no instar la ejecución del correspondiente plan parcial cuando pudo hacerlo. Asimismo, el hecho de que los derechos no estuvieran previamente consolidados determinó que los daños causados por la Disposición Transitoria Primera de la Ley $19 / 2003$, relativa a la suspensión del otorgamiento de autorizaciones turísticas previas y de licencias para edificios destinados a alojamientos turísticos hasta que se produjera la entrada en vigor de los Plan Territorial Especial de Ordenación Turística, no fueran objeto de indemnización. Por tanto, el Tribunal Supremo dio la razón a la Comunidad Autónoma canaria en relación con que no toda actuación de una administración que suponga la limitación de la extensión territorial de la urbanización da lugar a responsabilidad patrimonial de la Administración (Jiménez, 2011). De esta manera, se puso de manifiesto que no hubo daño real y efectivo para los reclamantes, y que, de haber existido, éste era antijurídico.

Del mismo modo, el Tribunal Supremo señaló la imposibilidad de determinar la existencia de lucro cesante, así como probar los posibles perjuicios derivados de la entrada en vigor de las distintas normas dictadas durante el proceso de moratoria turística (Decretos 4 y $126 / 12001$ y Leyes $6 / 2001$ y $19 / 2003$ ). Por tanto, las propias jurisprudencias del TSJC y del Tribunal Supremo determinaron que las medidas de contención del crecimiento urbanístico turístico no daban lugar a indemnización. Ello supuso un "ahorro" de 866,6 millones de euros para la Hacienda Pública canaria. De esta manera, la moratoria turística no ha tenido coste económico para la misma.

\subsection{La judicialización de la tercera moratoria turística (2009-actualidad)}

Con anterioridad a esa revocación por parte del Tribunal Supremo, se promulgó la Ley $6 / 2009$, de medidas urgentes en materia de ordenación territorial para la dinamización sectorial y la ordenación del turismo, dando inicio a lo que Simancas (2015) ha denominado como "tercera moratoria turística"; a diferencia de lo sucedido con la Ley 19/2003, ésta se aprobó sin consenso parlamentario y con la oposición del Grupo Parlamentario Socialista Canario. 
Esta norma fue la respuesta del ejecutivo canario a la necesidad de aportar alternativas a la eternización de la Ley 19/2003 y, sobre todo, evitar nuevas reclamaciones indemnizatorias por responsabilidad patrimonial incitadas por el éxito de las cinco sentencias judiciales firmes del TSJC. Para ello, la Ley 6/2009 planteó dos mecanismos.

En primer lugar, se eliminaron los plazos relativos a las adaptaciones a las Directrices de los instrumentos de ordenación territorial, modificando el régimen transitorio de la Ley 19/2003. Así, las determinaciones de los artículos 9 y 10 de la Ley 6/2009 desbloquearon y "descongelaron" cualquier procedimiento ajustado a tal régimen inter-temporal. Si bien este cambio de criterio puede interpretarse como un fracaso de las técnicas del derecho transitorio empleadas en la Ley 19/2003 o a un cambio de rumbo en la política legislativa del Gobierno y el Parlamento (Domínguez, 2010), en realidad, puso de manifiesto la necesidad de solucionar los ya fragantes incumplimientos por parte de las administraciones públicas competentes.

En segundo lugar, se abordó, con bastante retraso, el problema de las omisiones e imprevisiones de compensación de la Ley 19/2003 en relación con la afección a los derechos adquiridos $-y$, por tanto, consolidados - de los particulares en relación con dos supuestos: por un lado, para los titulares de autorizaciones previas que no deseaban materializarlos, debido, sobre todo, a la coyuntura económica del momento; y por otro, para la materialización de los aprovechamientos y derechos urbanísticos consolidados en los suelos urbanos y urbanizables sectorizados y ordenados con destino total o parcialmente turísticos, no desclasificados o descategorizados en virtud de la Disposición Adicional Cuarta de la Ley 19/2003 y no desarrollados. Para ello se habilitaron tres "salidas" o "escapatorias", con el fin de que los titulares afectados no tuvieran que seguir soportando un daño (artículo 17 de la Ley 6/2009).

La primera alternativa consistió en la sustitución del uso alojativo por otros lucrativos, como parques temáticos, actividades culturales, de ocio, de espectáculos, comerciales, deportivos, de restauración o similares; como se puede apreciar, esta opción constituyó la habilitación de una salida para los titulares que tenían suspendido su derecho a obtener autorizaciones previas en cualquier momento de vigencia de la moratoria turística. La segunda alternativa consistió en el traslado y la recategorización de los aprovechamientos urbanísticos de uso total o parcialmente turístico, con la consiguiente sustitución por nuevos usos (industriales, comerciales energéticos o residenciales) y su ubicación en la localización más adecuada, mediante convenio urbanístico, con los parámetros de ponderación adecuados y autorizados por el Gobierno.

La tercera de alternativa permitió que los titulares de los derechos optasen por la desclasificación de los suelos, transformándolos en rústicos de protección territorial, con la consiguiente solicitud de indemnización a cargo de la Administración autonómica a cambio de que el suelo saliera de la oferta turística durante un plazo mínimo de cinco años. Esta alternativa no sólo debía contribuir al propósito del Gobierno de Canarias de habilitar un instrumento dirigido a evitar nuevas reclamaciones de indemnizaciones por la vía judicial, sino, sobre todo, a limitar sus cuantías. Así, se planteó como un mecanismo para evitar que el TSJC fuera el único con potestad para regular estas últimas. Para ello se recurrió al denominado "método residual dinámico", en el que el valor del suelo con derechos urbanísticos consolidados se estimó en función de los costes de urbanización realizados, en lugar de las expectativas de ganancias que podrían haber obtenido su titular o por la edificabilidad permitida. 
Tras cumplirse el plazo preceptivo de seis meses, 56 peticiones se formalizaron ante la Consejería de Medio Ambiente y Ordenación Territorial del Gobierno de Canarias, de las que 54 se correspondieron con la tercera alternativa; la cuantía de las indemnizaciones ascendió a 778.364.536 euros. Ello resultó lógico, ya que esta opción fue la que otorgó unas garantías jurídicas mínimas en la coyuntura económica-financiera del momento, dando lugar, de nuevo, a procesos de rent seeking. Tras un silencio que la Administración entendió negativo y que provocó que los titulares de los suelos optaran por la reclamación en la vía administrativa, todos los expedientes, salvo un supuesto en que el promotor desistió continuar, fueron desestimados, dado que no constaba el cumplimiento los requerimientos del supuesto, sus promotores no acreditaron la titularidad del suelo y el destino turístico, los proyectos no se habían desarrollado por causas no imputables a la moratoria turística, los derechos urbanísticos consolidados no estaban consolidados (fundamentalmente por falta de plan parcial), así como las solicitudes se presentaron fuera de plazo. Ello determinó que los interesados interpusieran treinta y siete recursos contenciosos-administrativos. Treinta y tres terminaron en sentencias del TSJC, siendo ratificadas por el Tribunal Supremo. Estas no han determinado ningún tipo de indemnización, aunque reconocen el derecho a la tramitación de ese procedimiento para recalificar el suelo, de modo que el Gobierno de Canarias tiene que reiniciar el procedimiento.

\section{CONCLUSIONES}

La gobernabilidad incide en la capacidad del sistema político para dar respuesta a la demanda de los actores (individuos, grupos u organizaciones), como regulando los posibles conflictos a través de la adopción de soluciones eficaces, en igualdad de condiciones y bajo el argumento del interés general. La judicialización de las políticas públicas consiste en transferir la resolución de tales conflictos hacia la esfera judicial. Este "remedio" judicial ha marcado el devenir de la moratoria turística de Canarias, hasta el punto de que su dinámica es resultado de la sucesión de bandazos legislativos y cambios de criterios derivados, entre otros factores, de los "parches", improvisaciones, imprecisiones consecuencia de la sucesión de acciones legislativas y reacciones en forma de resoluciones judiciales. Ello conlleva una serie de implicaciones.

En primer lugar, la judicialización de las políticas públicas no es una iniciativa de los jueces. Supone el uso de la herramienta del amparo a la que los actores "perjudicados" recurren cuando consideran que sus derechos no están efectivamente garantizados por el poder ejecutivo o legislativo. Ello le permite traducir sus reivindicaciones al lenguaje del derecho y apelar a los tribunales de justicia para avanzar en ellas. Por tanto, la judicialización supone la utilización por tales actores de mecanismos legales para articular sus intereses a través de demandas judiciales. Ello es consecuencia de la rigidez de las decisiones judiciales, administrativas o legislativas (hard law) sobre la que suele sustentarse las políticas públicas turísticas. De esta manera, la judicialización demuestra que las áreas turísticas de litoral son espacios de conflicto, debido a los desequilibrios de poder público-privado, privado-privado y público-público. En este sentido, no hay que obviar que el "poder" no sólo se refiere a la capacidad de los actores para promover sus intereses (Simancas, 2018), sino también al papel de las estructuras políticas e institucionales (Bassols, 2011). 
En segundo lugar, la judicialización se produce cuando existen fallos en el proceso de formulación de tales políticas públicas (Secchi, 2010). Así, los actores perjudicados pretenden que los tribunales de justicia los solucionen y, por ende, satisfagan sus reivindicaciones y hagan valer sus intereses, habitualmente contrarios a los generales que deben representar cualquier política pública. Ello se debe a que estos actores "perjudicados" consideran a las instancias judiciales - y los procesos legales asociados - como los instrumentos de control más eficaces respecto a los "abusos" del poder político (Ferejohn, 2002), así como un intermediario válido entre ambas partes. Ello les permite presentar información que respalde sus intereses y descredite los puntos de vista del gobierno responsable del diseño de la controvertida política pública. Desde este punto de vista, la judicialización pone de manifiesto una escasa capacidad del poder legislativo para articular ciertas demandas. Además de incrementar las relaciones de confrontación entre las partes enfrentadas, la judicialización de cualquier política pública releva un fracaso de los enfoques de resolución de conflictos desde un enfoque de abajo a arriba (bottom-up), articulado en torno a un proceso permanente y cooperativo de implicación, diálogo intenso y continuo, acuerdo y consenso entre la pluralidad y diversidad de actores.

En tercer lugar, la judicialización supone la intrusión de los tribunales de justicia en un terreno reservado a los poderes ejecutivo y legislativo, con la consiguiente tensión entre política y justicia. Así, se exige que el poder judicial responda a asuntos que antes se consideraban eminentemente políticos. Ello supone un desplazamiento de protagonismo desde el poder legislativo al judicial, a la vez que una pérdida de centralidad de la autoridad legislativa, cuyo ejercicio y poder quedan limitados y regulados. Esto da lugar a una interesante paradójica: mientras los problemas políticos son resueltos en base a criterios jurídico-técnicos, los jueces son sometidos en su actuación a tensiones políticas. En el caso de la moratoria turística, las decisiones del poder judicial, en particular los del TSJC, han resuelto cuestiones propias de las instituciones políticas canarias, con el consiguiente traslado de la discusión política de la sede parlamentaria a la judicial.

Esta transferencia de poder ha sido muy criticada por algún sector doctrinal (Cámara, 2016; Marín, 2017), por considerarla como una grave lesión al principio democrático, dado el carácter no electivo de la judicatura. También se cuestiona la capacidad técnica de los jueces de disponer y analizar la información necesaria para la toma de decisiones. Asimismo, se sostiene, como opinión bastante generalizada, que las deficiencias de la legislación que sustenta cualquier decisión pública no constituyen razón suficiente para considerar que su solución definitiva resida en la vía de los contenciosos jurídico-administrativo. Del mismo modo, se alude a la falta de legitimidad del poder judicial para adoptar decisiones que involucran la determinación de políticas públicas (Gargarella, 1996; Waldron, 1999), e incluso, implementar y ejecutar las sentencias que requieren remedios más estructurales que dependen del poder político.

Por último, la judicialización implica básicamente una reacción judicial a las políticas públicas. Su introducción en el ciclo de las políticas públicas hace que el poder judicial adquiera una importante capacidad de interferencia e incidencia significativa en su reformulación. Así, este tipo de intervención de la jurisdicción contencioso-administrativa en el proceso de moratoria turística supone un ejemplo de matización de las decisiones públicas, al tener que 
equilibrar el idealismo inherente al interés general y el pragmatismo propio del sector privado. Ello determina que cuestiones propias de las instancias de competencia política se resuelvan por medio de las decisiones interpretativas derivadas de hechos, precedentes, procedimientos y argumentos propios del poder judicial. Esto ha ampliado el ámbito del judge-made law o de situaciones donde los jueces han creado un precedente judicial (Boscán, 2010), no exento de sus ideologías, prejuicios y preferencias al interpretar y aplicar las leyes.

Todo lo anterior hace que el poder judicial deje su tarea pasiva y de mero control para convertirse en un protagonista activo en la definición de las políticas públicas (Ansolabehere, 2005). Ello les está permitiendo participar en importantes debates de diversa índole (Couso, 2004), trascendiendo a la opinión pública. Ello ha obligado a los jueces a realizar su función bajo nuevos parámetros interpretativos, en cuanto la tarea jurisdiccional ya no responde a un modelo mecanicista y deductivista de aplicación de leyes, con el consiguiente margen amplio de actuación; por el contrario, ahora entran en juego las técnicas interpretativas propias de los principios constitucionales (la ponderación, la proporcionalidad, la razonabilidad, la maximización de los efectos normativos de los derechos fundamentales, etc.), que se completan con cláusulas de contenido abierto, normas de principio y conceptos indeterminados, que implican el ejercicio de la discrecionalidad.

\section{BIBLIOGRAFÍA}

Almeida, J., Costa, C. y Nunes da Silva, F. (2017). A framework for conflict analysis in spatial planning for tourism. Tourism Management Perspectives, 24, 94-106.

Alvarez, L. (2015). Judicialización de la política y soberanía popular: sobre el estatuto político de las resoluciones Judiciales. Revista Crítica de Ciências Sociais, 108, 95-110.

Ansolabehere, K. (2005). Jueces, política y derecho: particularidades y alcances de la politización de la justicia. Revista Isonomía, 22, 40-63.

Bassols, M. (2011). Gobernanza: una mirada desde el poder. En M. Bassols y C. Mendoza (coords.), Gobernanza: teoría y practicas colectivas. Barcelona: Anthropos - UAM Iztapalapa, 7-35.

Beritelli, P. y Laesser, C. (2011). Power dimensions and influence reputation in tourist destinations: Empirical evidence from a network of actors and stakeholders. Tourism Management, 32(6), 1.299-1.309.

Boscán, G. (2010). Judicialización y Politización en América Latina: una nueva estrategia para el estudio de la interacción entre los poderes públicos. Cuestiones Jurídicas, 4 (2), 51-83.

Cámara, J. (2016). El riesgo de la judicialización en España. Anuario da Facultade de Dereito da Universidade da Coruña, 20, 188-205.

Couso, J. (2004). Consolidación Democrática y Poder Judicial: los riesgos de la judicialización de la Política. Revista de Ciencia Política, 24 (2), 29-48.

Dente, B. y Subitats, J. (2013). Decisiones públicas. Análisis y estudio de los procesos de decisión en políticas públicas. Barcelona: Ariel.

Domingo, P. (2004). Judicialization of Politics or Politicization of the Judiciary? Recent Trends in Latin America. Democratization, 11 (1), 104-26. 
Domínguez, A. (2010). Derecho transitorio y Derecho intertemporal en el ordenamiento jurídico urbanístico autonómico canario. En J.J. Santana (coord.), Diez años de la Ley de Ordenación del Territorio de Canarias. Valencia: Tirant lo Blanch.

Dredge, D. (2006). Policy networks and the local organisation of tourism. Tourism Management, $27(2), 269-280$.

Dredge, D. (2010). Place change and tourism development conflict: Evaluating public interest. Tourism Management, 31(1), 104-112.

Elliott, J. (1997). Tourism: Politics and public sector management. London: Routledge.

Estévez, R. (2004). El urbanismo y la jurisdicción contencioso-administrativa. Estudio jurisprudencial. Revista de Derecho Urbanístico y Medio Ambiente, 208, 117-160.

Fajardo, Luís. 2006. Sistema de planeamiento en Canarias, Madrid: Editorial Montecorvo.

Feoli, M. (2014). Judicialización de la política y activismo judicial: ¿de qué estamos hablando? Anuario Facultad de Derecho - Universidad de Alcalá, 7, 1-28.

Ferejohn, J. (2002). Judicialización de la política, politización de la ley. Revista Mexicana de Ciencias Políticas y Sociales, 184, 13-49.

García, F. (2007). La nueva generación de Directrices Territoriales/Turísticas y la Sostenibilidad: la experiencia canaria. Estudios turísticos, 172-173, 89-96.

Gargarella, R. (1996). La justicia frente al gobierno. Sobre el carácter contramayoritario del poder judicial. Buenos Aires: Ariel.

Guarnieri, C. y Pederzoll, P. (2003). The power of judges. A comparative study of courts and democracy. Oxford: Thomas Oxford Social Legal Studies.

Hall, M. (2011). A typology of governance and its implications for tourism policy analysis. Journal of Sustainable Tourism, 19(4/5), 437-457.

Hennig, M. (2012). La jurisdicción constitucional entre judicialización y activismo judicial: existe realmente "un activismo" o "el" activismo. Estudios constitucionales, 10 (2), 429-454.

Jamal, T. y Getz, D. (2000). Community roundtables for tourism related conflicts: the dialectics of consensus and process structures. En B. Bramwell y L. Bernard (coord.), Tourism collaboration and partnerships: Politics, practice and sustainability. Clevedon: Channel View Publications.

Jiménez, A. (2011). Jurisprudencia ambiental en Canarias. Revista Catalana de Dret Ambiental, $2(1), 2-15$.

Marín, Ma (2017). Sobre la judicialización de la política: una aproximación desde el neoconstitucionalismo. Astrolabio. Revista Internacional de Filosofía, 20, 123-135.

Marín, Ma (2017). Sobre la judicialización de la política: una aproximación desde el neoconstitucionalismo. Astrolabio. Revista internacional de filosofía, 20.

Marzano, G. y Scott, N. (2009). Power in destination branding. Annals of Tourism Research, $36(2), 247-267$.

Mitchell, R., Agle, B. y Wood, D. (1997). Towards a theory of stakeholder identification: Defining the principle of who and what really counts. The Academy of management Review, 22 (4), 853-886.

O’Donnell, G. (2005). Afterwords. En R. Sieder, L. Schjolden y A. Angell (ed.), The judicialization of Politics in Latin America, New York: Palgrave MacMillan.

Secchi, L. (2010). Políticas públicas: conceptos, esquemas de análisis, estudios de casos. Sao Paulo: Cengage Learning. 
Sieder, R., Schjolden, L. y Angell, A. (2011). La judicialización de la política en América Latina. Bogota: Universidad Externado de Colombia.

Simancas, M. (2015). La moratoria turística de Canarias. La reconversión de un destino turístico maduro desde la Ordenación del Territorio. San Cristóbal de La Laguna: Universidad de La Laguna.

Simancas, M. (2018). Gobernabilidad territorial y relaciones de poder en los espacios turísticos: el conflicto derivado de las políticas públicas de renovación de los alojamientos turísticos de Canarias. Anales de Geografía de la Universidad Complutense, no 38(2), 435-460.

Stevenson, N.; Airey, D. y Miller, G. (2008). Tourism policy making: The policymakers' perspectives. Annals of Tourism Research, 35(3), 732-750.

Tate, Ch. y Vallinder, T. (1995). La expansión global del poder judicial: la judicialización de la política. En Ch. Tate y T. Vallinder (ed.), La expansión global del poder judicial. Nueva York: Universidad de Nueva York.

Valente, F., Dredge, D. y Lohmann, G. (2015). Leadership and governance in regional tourism. Journal of Destination Marketing \& Management, 4(2), 127-136.

Velasco, M. (2016). Entre el poder y la racionalidad: gobierno del turismo, política turística, planificación turística y gestión pública del turismo. Pasos. Revista de Turismo y Patrimonio Cultural, 14 (3), 577-594.

Villar, F. (2008). Planificación y diseño urbanístico. En E. Romero, M. Simancas y J. Febles (eds.), 1a Conferencia canaria de Ciudades y Pueblos Sostenibles. De Aalborg a Santa Úrsula: una aproximación al Desarrollo Sostenible en Canarias. Santa Cruz de Tenerife: Ayuntamiento de Santa Úrsula.

Villar, F. (2009). La política turística de Canarias. En M. Simancas (coord.), El impacto de la crisis en la economía canaria. Volumen I. San Cristóbal de La Laguna: Real Sociedad Económica de Amigos del País de Tenerife / Cabildo Insular de Tenerife.

Waldron, J. (1999). Law and Disagreement. Oxford: Oxford University Press.

Yang, J., Ryan, Ch. y Zhang, L. (2013). Social conflict in communities impacted by tourism, Tourism Management, 35: 82-93. 